ing the telescope, after unscrewing Band $v$. The scale, $\mathrm{E}$, is tixed to a support, and its weight is balanced by a counterpoise, P.
The apparatus is very light and convenient. The
use of it is not limited to the angular motions of use of it is not limited to the angular motions of a
mirror around a vertical axis. In order to adapt it for mirror around a vertical axis. In order to adapt it for
observations of angular motions around a horizontal
axis it suffices to remove the scale and its support axis, it suffices to remove the scale and its support, and
to fix the latter upon the horizontal cylinder situated a little above the bearings of the telescope.

Fig. 5 represents a telesteppe constructed by Dr. Edelmann, of Munich, and designed for use in laboratories
of physics. The apparatus is mounted upon a large of physics. The apparatus is mounted upon a large
wooden tripod, thus giving it great mobility
A parallelogram, $h, i, k, l$, serves for slight lateral A parallelogram, $h, i, k$, $l$, serves for slight lateral
movements, the screw, $\boldsymbol{d}$, for slight angular ones in a horizontal plane, and the screw, e, for angula
in a vertical plane.-La Lumiere Electrique.

$$
\text { [ELGCTRical Review.] }
$$

REIS' TELEPHONES

IN your issue of to-day you reproduce an extremely
interesting article from the SCIENTIFIC AMERTCAN which the following passage occurs respecting the early Which the following passage ocurs respecting the early
instruments described in 1861 by Reis, and in 1876 by Bell: transmitting speech, but by neither Bell nor Reis was
this power distinctly claimed. this power distinctly claimed. . . . Both inventors ap-
pear on the field with devices adapted for the same
end but neither with perfect distinctness claims this end, but neither with perfect disti
function as a part of the invention."

function as a part of the invention." assertions are no justified, so far as Reis is concerned, by the facts. He most unmistakably stated that his instrument was:
intended to transmit speech. The transmission of music by it was merely an after-thought. The very first sentence of the very first paper written
by "Reis on the telephone, in 1861 , is as follows:
"The surprising results in the domain of telegraphy

have often already suggested the question whether it may not also be posssble to communicate the very tones of speech [die Tonsprache selbst] to a distance."
There is no ambiguity here as to the intention Then There is no ambiguity here as to the intention. Then
he states his first prime difficulty. "How could a
single instrument reproduce at once the total actions of all the organs operated in human speech ?" His solution of that cardinal problem was the construction
of his first transmitter in the form of a model of the of his tirst transmitter in the form of a model of the
human ear, having at the back of the tympanum a metal microphone with spring contacts to imitate the
human ear-bones. He then said, after describing the

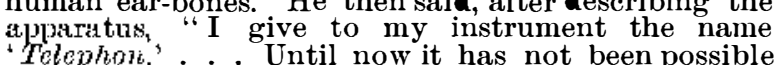
to reproduce the tones of human speech with a aistinctness to satisfy everybody. The consonants are for the
most part tolerably distinctly reprod uced, but the vowels not yet in an equal degree.
are quoted from the paper contributed by Reis in Dethe Physical Society of Frankfort-on-the-Main, of which Reis, Faraday, Brewster, and Whatstone were ing points:

human speech."
2. The "tones of human speech" included "co sonants" "and "vowels", in other words, what some from mere musical sounds.

3. The apparatus was more successful with consonants than with vowels, and though its artichuation
did not satisfy everybody, it is clear that it satisfied some. (This is not surprising, since the vowels are the
least important part of speech, and may be altered without affecting intelligibility, as is the case in the
differences between different dialects.) directions for using the inproved instrumed printed these directions told the person listening to the receiver how to signal instructions to the speaker at the trans.
mitting end: " One beat $=$ sing; two beats = speeak.

These instructions were circula
and England from 1863 to 1867 .

I cannot understand how, in the face of these thing it is that even those who are desirous of giving Reis
his just due so often fail in their endeavor. Nothing could be more appreciative, more fair, than the inten tions of the writer of the article in the SCIENTIF'T
AMERCAN. Yet he says Reis never claimed "this func AMERICAN. Yet he says Reis never claimed " this func
tion [i. e.. transmitting speech] as a part of his inven
tion." Never claimed this function! Why, that was the starting point of the invention, its pith, its marrow.
That was the dream which tor nine years had wrought That was the dream which for nine years had wrought
in his brain before he had made a single experiment. That was the essence of the invention which he brought
to the birth, and gave freely and without reservation to the scientific and commercial worlda the invention which he lived for, and wrapped himself up in, until
his all too early death. I say nothing here of the
abundant evidence of contemporary documents and abundant evidence of contemporary, documents and
contemporary witnesses. I leave Reis' own written and published words to speak for themselves. Litera scripta
manet. Not even the ability of the smartest Yankee manet. Not even the abilty of the smartest Yankee
lawyer can destroy the evidence to be found on the
slieteres of every great European library. Mr. Dickerson will find that out some day, perhaps when all the world (except himself has ceased to ignore the very stubborn fact that Philipp Reis aid actually write these unmis-
takable sentences in 1861 about his invention for transmitting speech.
I have spoken of Reis and what he described an

I have spoken of Reis and what he described as his
invention in 1861 and 1863 . Let me extract from Bell's specification (U. S.) of 1876 the passages which speech: ments may be put, such as as to which these instru transmission of noises or sounds of any kind." "
"One of the ways in which the armature may be set in vibration has been stated to be by wind. Another
mode is . by the human voice or by means of a "Iusical instrument." "The method of and apparatus for transmitting vocal or other sounds telegraphically." The language of Bell's specitication is more general
than that of Reis, but it is at the same time far less
significant or descriptive is Plenty of matter about significant or aescriptive. Plenty of matter about of Morse code, and "pitch," and "amplitude," and
"multiple telegraphy," but never a word about "speech," or "consonants," or "vowels," no instruc
tions how to signal to your friend when to "speak.
No the nearest approach to anything of that sort is "noises or sounds of any kind," " vocal or othe "noises, or sounds of any kind," vocal or other
sounds." But, weak though this may be, the use of
such general and feeble terms does not prove that Bell did not contemplate at that time the possible application of his "new and useful improvements in teleproves that Bell, on the 14 th of February, 1876 , was
still far behind the point attained by Reis on the 1 st of
Det December, 1861 . He was only fourteen years three abreast of that which Reis had accomplished without September 5, 1885 SILVANUS P. THOMPSON.

CAUSE OF THE ELECTRIFICATION OF CLOUDS WHEN the potential of an insulating medium increases as we recede from a conductor in its midst, this
latter is negatively electrified; a and this is the case with atter is negatively electrified, and this is the case with
he air in fine weather, so that Peltier's hypothesis that hectricity can be shown to be a fact. Even if some portions of the earth's surface are positively electrified,
as is indeed the case, they are so limited in extent as to leave the balance of the earth's charge of negative sign
A cloud arising near the earth's surface may be in electrical communication with it, and so become nega-
tively electrified, and on the dispersion of this cloud by tively electritied, and on the dispersion of this cloud by
evaporation the surrounding air would take up this negative charge. A cloud is a sufficiently good con-
ductor to allow of the potential at all points in it being practically the same. If, then, a cloud is formed in an
originally clear sky, this cloud will be electrified posi-
tively below, and negatively above If, now by the tively below, and negatively above. If, now, by the
action of the wind the two portions of the cloud becorve separated, we have two clouds charged with opposite
signs. Not only can this electrification by induction signs. Not only can this electrification by ind action
be shown to take place, but it may be further shown
that the quantity thus produced is sufficient to account

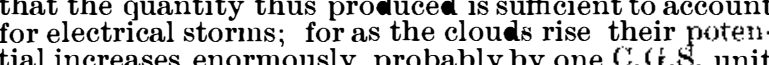
tial increases enormously, probably by one C.G.S. unit or each meter of elevation, so that the mere displace-
ment of clouds may give rise to differences of potential ment of clouds may give rise to differences of potential
corresponding to several thousand units.
The author, therefore, reduces the electrification of clouds to the existence of a negative charge of electrici al on the existed since its formation. $-H$. Pellat, in hour alde Physique.

CONSTRUCTION OF COPIES OF THE LEGAL OHM.

A FTER the Conference of. 1884, at which the legal ohm
was settled, the author was requested by the Minister was settled, the author was requested by the Minister
of Posts and Telegraph to make eropies of the unit of resistance. This he was able to do with great accuracy,
having placed at his disposal all the resources of the International Committee of Weights and Measures.
To calculate the resistance of a column of mercury, it is necessary to know (1st) the internal shape of the glass
tube, (2d) its capacity, (3d) its length; we can then use (a)
e formula,

$$
\begin{aligned}
\mathrm{R}=r \underset{v}{l^{2}}\{( & \left.\frac{1}{\mathrm{C}+x_{b}-x_{a}}+\frac{1}{\mathrm{C}+x_{a}-x_{b}}+\ldots\right) \mathrm{C}^{2} \\
& \left.+\frac{(n-m)^{2}}{n-m+x_{n}-x_{m}}\right\},
\end{aligned}
$$

where $r$ is the resistance of a column of unit length and
unit section, $z$ is length at zero of one division of the

te. the several divisions; $C$ the constant value $-a=c-b=$, etc. $. x_{a}, x_{b}$ the corrections to be made for
he individual divisions.
In order to introduce the mercurial column into the circuit, the connections were made by means of large
fasks full of mercury, into which the tube entered fasks full of mercury, into which the tube entered
through lateral tubulures. This method of connection through lateral tubulures. This method of connection
introduces. an additional resistance which must be
taken into account. It is obtained by adding to the ength of the tube a quantity equal to 0.82 time it diameter. The coefficient 0.82 , which had been de-
dianth duced by Lord Rayleigh from theoretical considera-
tions, has been experimentally verified by Mascart and The author made use of four tubes, two of green glass, two of flint glass. They were all about $12 \mathrm{~m}$. long, with a sectional area of 1 square $\mathrm{mm}$., and were
divided into millimeters for a length of $1.05 \mathrm{~m}$. They
had been prepared fourteen months before they were The calibration of the bore of the tubes was most carefully carried out in the same manner as is done in the case of delicate thermometers, viz., by accurately
measuring the length of a thread of mercury at various points of the tube.

To determine the capacity of one division of the tube, it was filled with a column of mercury 950 to
$1,000 \mathrm{~mm}$. long, which was in like manner measured in twenty aifferent positions, allowance being made for twenty different positions, allowance being made for
errors in the size of bore as determined by the preceding
operation, and also for the meniscus. The length having been thus nost carefully ascertained, the mercury
was emptied into a small glass vessel, and weighed with all the nicety possible with the very delicate instru-
ments of the Committee of Weights and Measures. ments of the Committee of Weights and Measures.
Adopting the value 13.5956 for the specific gravity of prised between any two divisions of the tube. It was found that in the measurements of lengths it was as this gave the true resistance within ing from the zero division, the exact length of each
tube was determined which should have a resistance of one legal ohm, and by sucessive trials the tube was
reduced to this length. The whole of the measure ments having been made at the prevailing temperature of the roonl. the coefficient of expansion of the glass was obtained, and the corrections nade to bring the The to zero. pleted, the resistances of the four tubevs were compared electrically among themselves. The bridge was made y one ohm in value, the fourth branch containing the
tube under test. The apparatus was completed by a
stretched wire with a sliding contact of $1 \mathrm{~mm}$. on the bridge wire caused a deflection of about $300 \mathrm{~mm}$. on the scale of the galvanometer. The value of the bridge wire had been aceurately deequivalent to 0.0000907 ohm. The comparisons were
made between each pair of tubes by two observers, the
author and Mr. De Nerville. author and Mr. De Nerville.
Admitting that the mean value 0.999994 ohm as deuced from the geometrical measurements is exact,
esistance of the four tubes comes out-

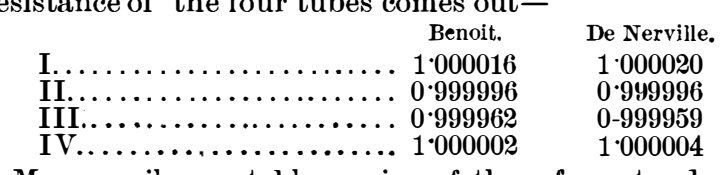

More easily portable copies of these four standards have also been made in glass tubes coiled into a spiral; was made accurately equal the one legal ohm.
With reference to the point of the purity of the merWith reference to the point of the purity of the mer-
cury employed, Mr. Benoit remarks that after several he action of hot nitric aciecury purified repeatedly by the action of hot nitric acid, then dried under a layer
of concentrated sulphuric acid, and finally passed over

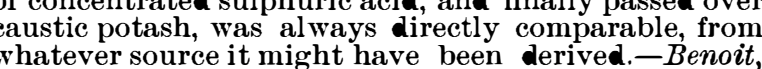
whatever source it might
in Journal de Physique.

\section{THE LAWS OF FRICTION}

By Marcel Deprez.*

THE purely mechanical part of one of the receiving Tachines designed for the experiment upon the elecric transmission of power, whicls will take place be-
ore long between Creil and Paris, having been completed a few days ago, I was obliged to go and receive
it that is to say to ascertain whether it was capable of revolving at the velocity of six hundred revolutions per ninute for a whole day without any heating re-
sulting therefrom. This condition having been fulabsorbed by passive resistances, which are in work part represented by the friction of the arles in their the machine, and suspended therefrom weights that were increased until the machine began to move. It
was ascertained in this way that a weight of 341 was ascertained in this way that a weight of 341
pourcts, acting tangentially upon a pulley 17 inches in diameter, was scarcely sufficient to keep the machine in motion when it had been set running at a flight veloci-
ty. The diameter of the journals being 4.5 inches, and the weight of the movale pieces being 8,360 of friction is nearly equalto one's, and that the resistant work due to such friction rises to 1,595 foot-pounds
when the axle of the machine is making a revolution. The nornal velocity having to be 400 revolutions per
ninute, it results from these figures that friction will bsorb about 11,000 foot-pounds per second.
This result approaches those that are daily being ascertained in the railway industry, where the coeffivelocity of freight trains to 0.015 .

Wecisive control, and having no dynamometer at my disposal, I em-
ployed the following method: I gave the machine an increasing velocity, and, at the moment the speed
reached about 600 revolutions per minute, I gave orders to allow the belt to fall that set it in motion. Then, a

\begin{tabular}{|c|c|c|c|c|c|c|}
\hline 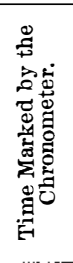 & 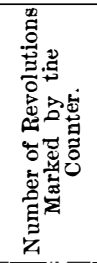 & 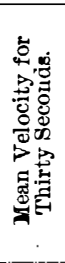 & 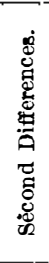 & 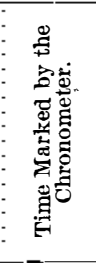 & 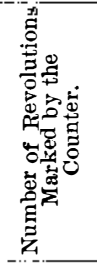 & 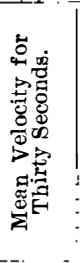 \\
\hline $\begin{array}{c}\text { nonds. } \\
0\end{array}$ & 0 & & & $\begin{array}{r}\text { eeonds. } \\
600\end{array}$ & 3,486 & \\
\hline 30 & 275 & & 15 & 630 & 3,588 & \\
\hline 60 & 535 & & 14 & 660 & 3,685 & 97 \\
\hline 90 & 781 & & 14 & 690 & 3,777 & 88 \\
\hline 120 & 1,013 & & 13 & 720 & 3,865 & \\
\hline 50 & 1,232 & & 12 & 750 & 3,949 & 80 \\
\hline 80 & 1,439 & & 11 & 780 & 4,029 & \\
\hline 10 & 1,635 & 100 & 10 & 810 & 4,105 & \\
\hline 10 & 1,821 & & 9 & 840 & 4,178 & \\
\hline 370 & 1,998 & & 8 & 870 & 4,248 & \\
\hline 00 & 2,167 & & 8 & 900 & 4,315 & \\
\hline 30 & 2,328 & 161 & 7 & 930 & 4,379 & \\
\hline 60 & 2,482 & & 7 & 960 & 4,440 & \\
\hline 90 & 2,629 & & 7 & 990 & 4,497 & \\
\hline 20 & 2,769 & & $\therefore 7$ & 1,020 & 4,550 & \\
\hline 50 & 2,902 & & 6 & 1,050 & 4,598 & \\
\hline 80 & 3,029 & & 6 & 1,080 & 4,640 & \\
\hline & 3,150 & & 1 & 1,110 & 4,673 & \\
\hline & 3,267 & & 5 & 1,140 & 4,697 & \\
\hline & 3,379 & & 5 & 1,154 & 4,702 & \\
\hline
\end{tabular}
he machine, I noted very accurately, every thirty seconds, the number of revolution
I thus obtained the annexed table.

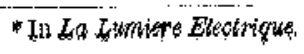


This table makes known the number of revolutions $\mid$ when railway and other interests must largely resort as a function of the time, and it is easy to deduce from to the artificial preparation of wood, in many parts of it the angular acceleration, and, consequently, the re$\mathrm{P}$, the total weicht of the masses in motion,

$\rho$, their radius of gyration,

, tire day,

$\boldsymbol{r}$, the radius of the journals,
$f$, the coefficient of friction,

and we shall have the following relations

$$
\mathrm{K}=\frac{2 \pi}{g} \mathrm{P} \rho^{2} \frac{d^{2} \omega}{d t^{2}} \quad t=\frac{\rho^{2}}{g r} \frac{d^{2} \omega}{i l t^{2}} .
$$

In the machine under consideration, the masses in motion were reduced to, say, two homogeneous cast-
iron disks 3.6 feet in diameter, weighing together 7,700 pounds. The steel axle weighed 660 pounds, but its motion of inertia was trifling with respect to that of
the disk. The radius of the journals was $2 \cdot 25$ inches. the disk. The radius of the journals was $2 \cdot 25$ inches.
By reason of the slowness with which the velocity decreased, we may, without committing sensible error,
replace the differentials by the finite differences, so
that in definite we may say that the coefficient of that in definite we may say that the coefficient of scribed in the tourth column of the table. Now, these second differences (and this is the main fact that results
from this experiment) vary from 15 to 3 . Thus, then, in the experiment cited, the coefficient of friction the velocity, and that its value varied in the ratio of 5 to 1 , while the velocity fell from 550 to 145 revolutions
per minute. From 145 to 120 revolutions per minute it vemained sensibly constant, in order to increase anew very rapidly in measure as the velocity tended towara 0.025 for a velocity of 550 revolutions per minute, and However astonishing this figure may at first sight appear, it seems to me to be beyond dispute, being made with the revolution counter succeed one another, and the fact that the machine revolved for 19 minutes and 14 seconds before stopping, thus making 4,700 revomean coefficient of friction, calculated by taking these

THE PRESERVATION OF TIMBER.*

Report of THE CoMmitee OF THe AMerican SoCIETY OF CIVIL ENGINEERS ON THE PRESERVAthe Annual Convention, June 25, 1885.

THE committee on the "Preservation of Timber" was appointed early in 1880 . the census of that year, it had become evident to engineers, from the increasing price and growing difficulty many parts of the United States, that several of the sources of such supplies were being rapidly exhausted, resort to the artificial preparation of wood against decay, as had been successfully done for years in

The principal questions before the committee were to determine which methods of preserving timber best adapted to the needs and current practice in thi
country. Designing to base its report only upon well ascer
tained facts, the committee urdertook to gather a fully as practicable the records of the experiments order to compare them with each other, and with the results in Europe.

During the first year the committee accomplished but little. It had to overcome the public indifference the investigation, as it was goubted whether there try. It also had to ascertain where the much-scat tered information desired was to be found.

spondence, in order to find who possessed the data of past experiments, and who would be willing to impart of answer was printed. It corresponded with some 350 persons, rathered and studied some 55 pamphlets, some 147 experiments, which are hereinafter tabulated and commented upon.

When this information began to come in, the com-
mittee found it very confusing. Not only were there mittee found it very confusing. Not only were ther were expressed, but the facts seemed to contradict give different results, and these again differed from th European experience. to the Washington Convention in 1882 , and asked for more time to ascertain how each experiment had been carried out, and to sift the evidence.
This was very tedious, both because there were few rely upon personal recollections, and because the various persons who possessed such remembrance (and
sometimes it required three or four to recollect the details of one experiment) had changed their busines connection, and were scattered all over the country.
The committee here wishes to express its gratefu thanks for the universal kindness and care with which its inquiries have been answered by the various gentlein the records of experiments (last column). What their assistanis

NECESSITY FOR PRESERVING TIMBER.

The data on forestry gathered for the census of 1880

mas now arrived
As something may be accomplished by economy in
the use of timber and by preventing waste, the Washington Convention instructed the committee to include the latter subject in its report. This was intrusted to Mr. Francis Collingwood, who, from past researches and who has furnished a monograph on the subject, which will be found in Appendix No. 1, and to which
particular attention is invited. From this it appears that our Northern white pine ered as inexhaustible, now bid fair to yield but eleven years more of supply at the existing rate, and that 'These facts must soon produce advancing prices The farther, but still accessible, supplies are now being
drawn upon, and as soon as they are exhausted, prices drawn upon, and as soon as they are exhausted, prices vances have alreaty taken place, and in the older
States, lumber, timber, and fies are ruling at about double the rates prevailing thirty or forty years ago,
with a prospect that in less than half that time they will approximate European prices.
Timber has hitherto been so abundant and cheap in the United States that there has been butlittle induce-
ment for economy in preserving it artificially against eeen experimenting on the subject for more than a much as to be effective the work must be well done, it
was found here to be relatively too costly.
So long as wood was cheap, the cost of efficient preparation, including interest on plant and price of antiprics, was so great in proportion to the ruling timber prices twenty or thirty years ago that timber preserva-
tion did not pay. It was cheaper to let it rot in the
good old way, and many corporations and individuals, after trying experiments which were more or less sucessful, abandoned the work as not conferring benefits Fresh attention was attracted to the subject by the
publication of Messrs. Colburn and Holley's report upon European railways in 1858. In this very valuable treatise a chapter was devoted to sleepers, and to their
preparation against decay. This brought about the erection of some wood-preparing works by the larger
railways, and a plentiful crop of so-called inventions

The chief efforts of this crop of inventors were either
The Europe. They also proposed to reduce the time of
application. These efforts to produce effects with of small doses to the preservation of timber, did not meet with success. The inventors patented sundry preparations and methods, took such jobs as they could
obtain, sold whatever State and county rights they
could, and retired from the field when the insufficiency
or danger of their process becane apparent. We will hereafter describe some of these processes; and it may fairly be expected, should the publication of this
report lead to renewed attention to the subject of wood ions based on the method of "how not to do it."
it

It will hereafter be seen that some of the processes
which have been successful abroad led to indifferent or which have been successful abroad led to ind ifferent or
unsatisfactory results in this country. The committee found them in the unobservance of some of the condi-
tions which have been found necessary to success in Eurnpe. These relate to the time occupied in treat-
ment, to the methods pursued, to the strength and quality of the molutions employed, and especially to the fact that the Europeans chiefly operate upon seasoned
timber, while we have generally operated upon green
or freshly cut timber, which requires a different treatment.
These various points will be touched upon in describ. ing the principal experiments which have been. con-
ducted in this country, and will be found fairly to the results-differences so great as to have led many managers of important interests to doubt whether any method of wood prepa
said to be successful.

PRESERVING PROCESSES.

Although experiments in wood preserving now date uented with seems nearly endless, * there are but fewantiseptics which have stood the test of time, or have Special activity seems to have set in with the Rail-
way Era, and the consequent demand for timber which had to be exposed to the weather. and the committee has collected 104 issued in the
United States. Few of them, however, have proved permanently successful.
Mr. W. P. Moir, in a paper read in 1869 before the Philosophical Society of Glasgow, gives the following list of the names of the pate

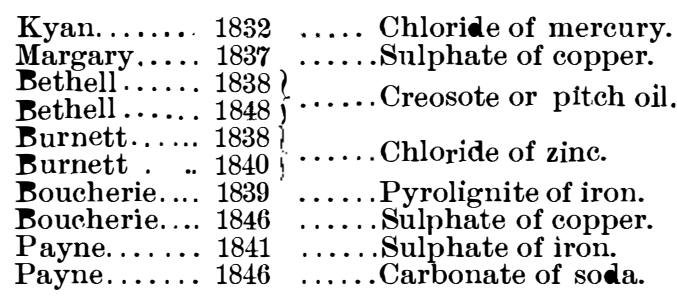

* In a treatise on the preservation of timber, by $\mathbf{~ W m}$. Chapman, civ
engineer problished in London in 1817 , will be found records of exper
ments with, and mode of application of, the following substances :

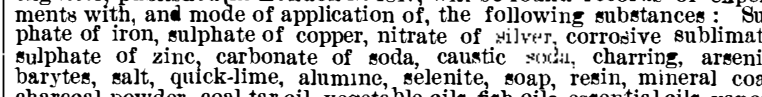

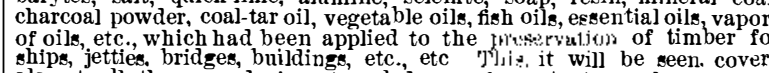
almost all the ground since traveled over by patentees, who are con-
stantly even now experimenting with and patentingsubstances which had
been investigated and discarded by $\mathbf{M}$, Chapman and his predecessors, ment for economy in preserving it artificially against guantity than had been found to be requisite in
,
Concerning the modes of application, Mr. Moir says: The methods employed pristically in working these suction, and pressing in close vessels; Kyan and Margary ployed the second; and Payne, Burnett, and Bethell
employed the third, which wasalso latterly adopted by
Boucherie. The first and third methods required that Boucherie. The first and third methods required that These original patents have now all expired, and the use of the antiseptics which have proved most effective plication, such as steaming in closed cylinders, to
pent plication, such as steaming in closed cylinders, to
season the wood and remove the sap, and various devices to prevent the antiseptic from washing out upon exposure. Whether it will pay to use them each eneral terms that we now know the antiseptics which are most effective, and that the best modes of applica-
tion are also pretty well known. It will much simplify matters, for those who have
are also pretty well known. It will much simplify matters, for those who have
not made a study of the subject, to group, so far as the best known processes, and to include therein
various modifications which had sufficient of novelty
to form the basis for a new patent. We have, therefore, classified the various experiments in the United
States, concerning which we have been enabled to States, concerning which we have been ena
gatherinformation, under the following heads

1. Kyanizing - or use of corrosive sublimate.

Creosoting-or use of creosote oil.

Miscellaneous-or use of various substances

In referring to these experiments, we have endeavornd where full information seemed desirable, we give; Many of these gentlemen took sufficient interest in
thames of their respective writers. Many of these gentlemen took sufficient interest in
the matter to hunt up and send to the committee specimens of the timber operated upon in these experiments. position of Railway Appliances, held in Chicago in June, 1883 , and are now deposited in the museum of
the Civil Engineers' Club of the University of Illinois, at Champaign, Illinois.

As already stated, kyanizing was first introduced in
It consists in steeping the timber in a solution of corrosive sublimate, probably the most powerful anThe original proportions were one pound of the dry salt to four gallons of water, or a solution three per
cent. strong by weight. Of this the timber absorbed six or seven pounds of salt per "load" of 50 cubic feet,
or say ten to twelve pounds per 1,000 feet, board measure. As the price of this chemical was then $\$ 1.25$
mear per pound, it cost some $\$ 12$ or $\$ 14$ per 1,000 feet, board Ultimately the solution was reduced to one pound to
ten gallons, or even fifteen gallons, of water $(1 \cdot 2$ to 0.8 per cent. by weight), and with the latter the timber 1,000 feet, board measure. "Boucherie" process, but the timber was found to absorb too much of the salt, and some of the solution necessarily ran to waste. The
cost induced some of the contractors to further reduce
the strength of the solution. To speak in plain terms, thed them to cheating, and kyanizing fell into con-
tempt in England. Moreover, the process is very tempt in England. Moreover, the process is very tedious, because of the length of time required to im-
pregnate the timber, and there are now but two private
establishments in this country (which will be noticed urther on) which kyanize timber for their own use. At this salt now costs fifty to sixty cents a pound, and as an absorption of four or five pounds per 1,000
feet, board measure, is considered sufficient, kyanizing now costs about $\$ 6$ per 1,000 feet, board measure. depend upon the price of the timber and its subsethe following table of sixteen experinents, which have been made in this country, and we add the comments which they seem to require.

COMMENTS ON KYANIZING EXPERIMENTS.

Concerning the first experiment in the list, General
J. Cram says, in a report to the Chief of Engineers, T. J. Cram says, in a report to the Chief of Engineers, "I have found our northern red cedar treated with limate), after 22 years' exposure, lying on a slope of strong limy soil, to have gone to decay, especially the Michigan, resting upon the same kind of dirt, dozed and rotted twenty years after the treatment. Maryland, kyanized and laid upon a limy soil, some miles north of Baltimore, in 1838 , I saw tested 11 years
afterward, and then perfectly sound and more solid untreated but laid at the same time, in the same kind of soil and exposure with the treated ones, lasted only
7 years before they required renewal. "This experiment of kyanizing timber was the first,
I believe, ever practiced in our country. Ties enough were treated for 1 mile of track, costing $121 / 2$ cents per cubic foot of timber. The process, howerer, was so kyanized ties are yet sound. At that time the un. Diligent inquiries among the present officers and
some of the former officials of the Northern Central Railroad have failed to elicit any further information
as to the final result of this experiment. It is very as to the final result of this experiment. It is very
evident, however, why it was not followed up. Crossties usually contain from 2 to $31 / 2$ cubic feet of timber,
which, at $121 / 2$ cents per cubic foot, would make the which, at $121 / 2$ cents per cubic foot, would make the
cost of treatment, at that time, from 25 to 44 cents per tie. This is wholly out of proportion with their original cost, which was 14 to 16 cents apiece. The
same ties would now cost untreated about 50 cents apiece, and at the reduced cost of corrosive sublimate
could be kyanized for 15 to 25 cents each. 